\title{
APLIKASI KORELASI SPEARMAN UNTUK MENGANALISIS HUBUNGAN ANTARA STRES KERJA DENGAN KEPUASAN KERJA PEGAWAI BERDASARKAN GENDER (STUDI KASUS : DINAS PERHUBUNGAN KOTA AMBON)
}

\author{
Oleh: ${ }^{1}$ R. Mustamu, ${ }^{2}$ F. Y. Rumlawang, ${ }^{3}$ Y.A. Lesnussa \\ ${ }^{1,2,3}$ Jurusan Matematika Fakultas MIPA Universitas Pattimura \\ e-mail: ${ }^{1}$ viki.revaldo@yahoo.com,${ }^{2}$ rumlawang@yahoo.com, ${ }^{3}$ yopi_a lesnussa@yahoo.com
}

\begin{abstract}
Abstrak:
Ada dua hal yang mempengaruhi gender dalam suatu organisasi, yaitu stres kerja dan kepuasan kerja. Stres kerja adalah suatu kondisi ketegangan yang mempengaruhi emosi, proses berpikir dan kondisi seseorang, sedangkan kepuasan kerja adalah keadaan emosional pegawai dimana terjadi ataupun tidak terajdi titik temu antara nilai balas jasa kerja pegawai dari organisasi dengan tingakat nilai balas jasa yang memang diinginkan oleh pegawai yang bersangkutan. Penelitian ini bertujuan untuk menganalisis hubungan antara stres kerja dengan kepuasan kerja pegawai pada Dinas Perhubungan Kota Ambon. Pengumpulan data primer dilakukan dengan menyebarkan kuesioner. Metode yang dilakukan dalam penelitian adalah dengan menggunakan uji korelasi spearman. Hasil uji korelasi spearman menunjukan bahwa terdapat atau tidaknya hubungan antara stress kerja yang diukur melalui variabel peran individu dalam organisasi, tuntutan tugas, hubungan dalam organisasi, dan faktor luar organisasi dengan kepuasan kerja antara pegawai pria dan wanita.
\end{abstract}

Kata Kunci: Stres Kerja, Kepuasan Kerja, Gender.

\section{Pendahuluan}

Dalam suatu organisasi terdapat beberapa unsur pendukung untuk menjamin suksesnya organisasi tersebut. Salah satu unsur yang paling mendominan adalah Sumber Daya Manusia, karena sumber daya manusia dinyatakan sebagai strategi perancangan, pelaksanaan dan pemeliharaan untuk mengelola manusia untuk kinerja usaha yang optimal termasuk kebijakan pengembangan dan proses untuk mendukung strategi. Dalam sumber daya manusia terdapat perbedaan dan fungsi peran dalam suatu organisasi yang dikonstruksikan oleh masyarakat, serta tanggung jawab pria dan wanita dimana perbedaan ini disebut Gender. Ada dua hal yang mempengaruhi gender dalam suatu organisasi, yaitu stres kerja dan kepuasan kerja. Stres kerja adalah suatu kondisi ketegangan yang mempengaruhi emosi, proses berpikir dan kondisi seseorang (Handoko, 2008: 200) sedangkan kepuasan kerja adalah keadaan emosional pegawai dimana terjadi ataupun tidak terjadi titik temu 
antara nilai balas jasa kerja pegawai dari organisasi dengan tingkat nilai balas jasa yang memang diinginkan oleh pegawai yang bersangkutan. Dinas Perhubungan merupakan salah satu dinas pekerjaan dimana lingkungan kerjanya sangat menuntut disiplin kerja yang tinggi dari pegawai untuk menghadapi persaingan dunia. Jumlah pegawai pria lebih dominan pada bidang kerja ini dibanding jumlah pegawai wanita. Pegawai pria lebih banyak ditempatkan pada bagian mekanik dan operasional lapangan sedangkan pegawai wanita ditempatkan pada bagian keuangan, administrasi, auditing dan controller. Namun, jika ditinjau lebih lanjut meskipun tuntutan peran mereka berbeda, boleh jadi pegawai pria memiliki stres kerja yang lebih tinggi dibanding pegawai wanita atau sebaliknya pegawai wanita yang memiliki stres kerja yang tinggi. Untuk mengetahui bagaimana hubungan antara stres dan kepuasan dapat digunakan Metode Korelasi Spearman. Metode korelasi spearman adalah metode yang digunakan untuk mengukur tingkat atau eratnya hubungan antara dua variabel yaitu variabel bebas dan variabel terikat yang berskala ordinal.

\section{Kajian Pustaka}

Korelasi adalah salah satu teknik statistik yang digunakan untuk mencari hubungan antara dua variabel atau lebih yang sifatnya kuantitatif dan kualitatif (Departemen Biostatistik FKM UI, 2009: 37). Menurut Young, 1982 (dalam Departemen Biostatistik FKM UI, 2009: 37), ukuran korelasi yang dapat digunakan adalah sebagai berikut:

- $0,70-1,00$ (baik plus atau minus) menunjukkan hubungan yang kuat.

- $0,40-<0,70$ (baik plus atau minus) menunjukkan hubungan yang tidak terlalu kuat.

- 0,20 - < 0,40 (baik plus atau minus) menunjukkan adanya korelasi yang rendah.

- $<0,20$ (baik plus atau minus) berarti dapat diabaikan.

Korelasi Spearman digunakan untuk mencari hubungan atau untuk menguji signifikansi hipotesis asosiasi jika masing-masing variabel yang dihubungkan berbentuk ordinal, dan antara variabel tidak boleh sama (Departemen Biostatistik FKM UI, 2009: 40).

Teknik Korelasi Spearman digunakan untuk menganalisis data penelitian yang mempunyai karakteristik sebagai berikut (Arokhman, 2009: 27): 
85 | al-Khwarizmi, Volume III, Edisi 1, Maret 2015, Hal. 83 - 92.

1. Hipotesis yang diajukan hipotesis asosiatif.

2. Skala data ordinal.

3. Data harus berdistribusi normal.

4. Taraf nyata $(\alpha)=5 \%$

Dasar dari penggunaan korelasi spearman adalah rangking (peringkat). Rumus yang digunakan adalah:

$$
r_{s}=1-\frac{6 \sum d^{2}}{n\left(n^{2}-1\right)}
$$

Keterangan:

$r_{s}=$ Koefisien korelasi spearman

$\mathrm{d}=$ Selisih antara 2 peringkat variabel

$\mathrm{n}=$ Jumlah sampel

Pada penelitian ini, peneliti ingin mengetahui apakah terdapat hubungan antara stres dan kepuasan kerja, sehingga uji yang digunakan dalam penelitian ini adalah uji dua sisi.

1. Hipotesis

$\mathrm{H}_{0}$ : Tidak ada hubungan antara variabel $\mathrm{X}$ dan $\mathrm{Y}$.

$\mathrm{H}_{1}$ : Ada hubungan antara variabel $\mathrm{X}$ dan $\mathrm{Y}$.

2. Nilai $\alpha$ dan rs tabel

$$
\alpha=5 \%=0,05, \mathrm{n}=20, \mathrm{rs}_{0,05 ; 20}=0,447
$$

3. Kriteria Pengambilan Keputusan

Nilai rs $_{\text {hitung }}>\mathrm{rs}_{\text {tabel }}$ maka $\mathrm{H}_{0}$ ditolak

Nilai $r s_{\text {hitung }} \leq r s_{\text {tabel }}$ maka $\mathrm{H}_{1}$ diterima

4. Membuat Tabel Penolong Korelasi Spearman

Tabel Penolong Korelasi Spearman

\begin{tabular}{|c|c|c|c|c|c|c|}
\hline No & $\mathrm{X}$ & $\begin{array}{c}\text { Rank } \\
\mathrm{X}\end{array}$ & $\mathrm{Y}$ & $\begin{array}{c}\text { Rank } \\
\mathrm{Y}\end{array}$ & $\begin{array}{c}\mathrm{X}-\mathrm{Y} \\
\mathrm{d}\end{array}$ & $\mathrm{d}^{2}$ \\
\hline 1 & $\cdot$ & $\cdot$ & $\cdot$ & $\cdot$ & $\cdot$ & $\cdot$ \\
$\cdot$ & $\cdot$ & $\cdot$ & $\cdot$ & $\cdot$ & $\cdot$ & $\cdot$ \\
$\cdot$ & $\cdot$ & $\cdot$ & $\cdot$ & $\cdot$ & $\cdot$ & $\cdot$ \\
$\cdot$ & $\cdot$ & $\cdot$ & $\cdot$ & $\cdot$ & $\cdot$ & $\cdot$ \\
$\mathrm{n}$ & $\cdot$ & $\cdot$ & $\cdot$ & $\cdot$ & $\cdot$ & $\cdot$ \\
\hline \multicolumn{1}{|r}{} \\
\hline
\end{tabular}

5. Uji Statistik Korelasi Spearman

6. Kesimpulan

$$
r s=1-\frac{6 \sum d^{2}}{n\left(n^{2}-1\right)}
$$

$\mathrm{H}_{0}$ di terima atau $\mathrm{H}_{1}$ ditolak 
Validitas atau tingkat ketepatan, kejituan, atau keakuratan adalah kemampuan suatu alat ukur untuk mengukur apa yang seharusnya diukur. Dengan kata lain, instrumen tersebut dapat mengukur variabel (konstruk) yang diinginkan oleh periset (Mas'ud, 2004: 68). Validitas dihitung dengan membandingkan antara nilai $r$ hitung dengan nilai $r$ tabel. Jika nilai $r$ hitung lebih besar dari nilai $r$ tabel maka pernyataan tersebut valid.

Reliabilitas atau tingkat keandalan, ketetapan (konsistensi) adalah tingkat kemampuan instrumen riset untuk mengumpulkan data secara konsisten dari sekelompok individu. Instrumen yang memiliki tingkat reliabilitas yang tinggi cenderung menghasilkan data yang sama tentang suatu variabel atau unsur-unsurnya, jika diulangi pada waktu yang berbeda pada sekelompok individu yang sama, sehingga instrumen tersebut dapat dinilai reliabel (Mas'ud, 2004: 68). Reliabilitas diukur dengan menggunakan Cronbach's Alpha $(\alpha)$ dimana hasil yang menunjukkan di atas 0,60 dapat dikatakan reliabel (Ghozali, 2009: 46).

\section{Hasil dan Pembahasan}

Dinas Perhubungan Kota Ambon merupakan salah satu lembaga pemerintahan yang memegang peranan penting di kota Ambon. Dari awal berdirinya pada tahun 1972 sampai dengan sekarang, Dinas Perhubungan Kota Ambon memiliki jumlah pegawai yang sangat banyak baik pria maupun wanita. Dalam menjalankan fungsi perannya sebagai pegawai, mereka sering mengalami stres dan puas dalam bekerja. Untuk menganalisis bagaimana hubungan antara stres dan kepuasan kerja, dilakukan langkah-langkah sebagai berikut :

Data Kuesioner terdiri dari 4 variabel strers (X1, X2, X3, X4) dan 1 variabel kepuasan dimana variabel kepuasan untuk pria (Y1) dan untuk wanita (Y2). Variabel-variabel ini terdiri dari 3 pernyataan dengan pmbagian sebagai berikut :

a. Peranan Individu Dalam Organisasi $\left(\mathrm{X}_{1}\right)$

Pernyataan $1=\mathrm{A} 1$, Pernyataan $2=\mathrm{A} 2$, Pernyataan $3=\mathrm{A} 3$

$\mathrm{X}_{1}=\mathrm{A} 1+\mathrm{A} 2+\mathrm{A} 3$

b. Tuntutan Tugas $\left(X_{2}\right)$

Pernyataan $4=\mathrm{B} 1$, Pernyataan $5=\mathrm{B} 2$, Pernyataan $6=\mathrm{B} 3$

$\mathrm{X}_{2}=\mathrm{B} 1+\mathrm{B} 2+\mathrm{B} 3$

c. Hubungan Dalam Organisasi $\left(\mathrm{X}_{3}\right)$

Pernyataan $7=\mathrm{C} 1$, Pernyataan $8=\mathrm{C} 2$, Pernyataan $9=\mathrm{C} 3$

$\mathrm{X}_{3}=\mathrm{C} 1+\mathrm{C} 2+\mathrm{C} 3$ 
87 | al-Khwarizmi, Volume III, Edisi 1, Maret 2015, Hal. 83 - 92.

d. Faktor Luar Organisasi $\left(\mathrm{X}_{4}\right)$

Pernyataan $10=\mathrm{D} 1$, Pernyataan $11=\mathrm{D} 2$, Pernyataan $12=\mathrm{D} 3$

$\mathrm{X}_{4}=\mathrm{D} 1+\mathrm{D} 2+\mathrm{D} 3$

e. Kepuasan Kerja $\left(\mathrm{Y}_{1}\right)$

Pernyataan $1=\mathrm{E} 1$, Pernyataan $2=\mathrm{E} 2$, Pernyataan $3=\mathrm{E} 3$

$\mathrm{X} 4=\mathrm{E} 1+\mathrm{E} 2+\mathrm{E} 3$

f. Kepuasan Kerja $\left(\mathrm{Y}_{2}\right)$

Pernyataan $1=\mathrm{E} 1$, Pernyataan $2=\mathrm{E} 2$, Pernyataan $3=\mathrm{E} 3$

$\mathrm{X} 4=\mathrm{E} 1+\mathrm{E} 2+\mathrm{E} 3$

Uji Validitas dilakukan terhadap pernyataan-pernyataan pada masing-masing variabel dengan menggunakan software SPSS. (valid). Uji Reliabilitas dilakukan terhadap pernyataan-pernyataan pada masing-masing variabel dengan menggunakan software SPSS. (reliabel)

Data Sampel Pria

\begin{tabular}{|c|c|c|c|c|c|}
\hline No & $\left(\mathrm{X}_{1}\right)$ & $\left(\mathrm{X}_{2}\right)$ & $\left(\mathrm{X}_{3}\right)$ & $\left(\mathrm{X}_{4}\right)$ & $\left(\mathrm{Y}_{1}\right)$ \\
\hline 1 & 7 & 3 & 3 & 4 & 5 \\
\hline 2 & 7 & 8 & 10 & 10 & 8 \\
\hline 3 & 4 & 8 & 7 & 5 & 8 \\
\hline 4 & 3 & 10 & 3 & 4 & 8 \\
\hline 5 & 6 & 6 & 4 & 5 & 5 \\
\hline 6 & 9 & 9 & 8 & 8 & 3 \\
\hline 7 & 9 & 4 & 8 & 6 & 8 \\
\hline 8 & 5 & 3 & 5 & 3 & 7 \\
\hline 9 & 6 & 5 & 3 & 7 & 8 \\
\hline 10 & 5 & 8 & 3 & 9 & 3 \\
\hline 11 & 3 & 9 & 6 & 6 & 6 \\
\hline 12 & 5 & 5 & 3 & 5 & 4 \\
\hline 13 & 11 & 6 & 3 & 4 & 3 \\
\hline 14 & 6 & 6 & 4 & 9 & 4 \\
\hline 15 & 4 & 5 & 7 & 4 & 5 \\
\hline 16 & 9 & 8 & 3 & 3 & 6 \\
\hline 17 & 7 & 4 & 3 & 7 & 4 \\
\hline 18 & 8 & 6 & 3 & 9 & 5 \\
\hline 19 & 11 & 6 & 6 & 8 & 6 \\
\hline
\end{tabular}

Data Sampel Wanita

\begin{tabular}{|c|c|c|c|c|c|}
\hline No & $\left(\mathrm{X}_{1}\right)$ & $\left(\mathrm{X}_{2}\right)$ & $\left(\mathrm{X}_{3}\right)$ & $\left(\mathrm{X}_{4}\right)$ & $\left(\mathrm{Y}_{2}\right)$ \\
\hline 1 & 4 & 3 & 3 & 3 & 3 \\
\hline 2 & 3 & 3 & 6 & 3 & 6 \\
\hline 3 & 7 & 7 & 6 & 10 & 7 \\
\hline 4 & 6 & 3 & 6 & 4 & 3 \\
\hline 5 & 4 & 5 & 4 & 4 & 4 \\
\hline 6 & 3 & 7 & 6 & 10 & 4 \\
\hline 7 & 6 & 6 & 9 & 9 & 5 \\
\hline 8 & 3 & 7 & 4 & 4 & 7 \\
\hline 9 & 3 & 5 & 3 & 4 & 3 \\
\hline 10 & 7 & 6 & 7 & 4 & 7 \\
\hline 11 & 11 & 8 & 11 & 8 & 5 \\
\hline 12 & 3 & 4 & 4 & 5 & 3 \\
\hline 13 & 6 & 3 & 4 & 3 & 4 \\
\hline 14 & 5 & 11 & 6 & 6 & 7 \\
\hline 15 & 5 & 13 & 4 & 4 & 9 \\
\hline 16 & 4 & 3 & 3 & 4 & 3 \\
\hline 17 & 7 & 3 & 3 & 4 & 3 \\
\hline 18 & 7 & 7 & 6 & 7 & 6 \\
\hline 19 & 3 & 4 & 3 & 5 & 3 \\
\hline
\end{tabular}

Sumber : Data primer yang diolah 2015.

Kasus Pria.

Contoh: Menghitung Korelasi Spearman antara Tuntutan Tugas $\left(\mathrm{X}_{2}\right)$ dengan Kepuasan Kerja $\left(\mathrm{Y}_{1}\right)$ pegawai pria.

1. Hipotesis

$\mathrm{H}_{0}$ : Tidak ada hubungan antara Tuntutan Tugas dengan Kepuasan Kerja.

$\mathrm{H}_{1}$ : Ada hubungan antara Tuntutan Tugas dengan Kepuasan Kerja.

2. Nilai $\alpha$ dan rs tabel 
$\alpha=5 \%=0,05, \mathrm{n}=20, \mathrm{rs}_{0,05 ; 20}=0,447$

3. Kriteria Pengambilan Keputusan

Nilai $r s_{\text {hitung }}>r s_{\text {tabel }}$ maka $\mathrm{H}_{0}$ ditolak

Nilai $r s_{\text {hitung }} \leq r s_{\text {tabel }}$ maka $\mathrm{H}_{0}$ diterima

4. Membuat Tabel Penolong Korelasi Spearman

Tabel Penolong Untuk Menghitung Korelasi Spearman

\begin{tabular}{|c|c|c|c|c|c|c|}
\hline NO & $\left(\mathrm{X}_{2}\right)$ & $\begin{array}{c}\text { Rank } \\
\left(\mathrm{X}_{2}\right)\end{array}$ & $\left(\mathrm{Y}_{1}\right)$ & $\begin{array}{c}\text { Rank } \\
\left(\mathrm{Y}_{1}\right)\end{array}$ & $\begin{array}{c}\mathrm{X}-\mathrm{Y} \\
(\mathrm{d})\end{array}$ & $\left(\mathrm{d}^{2}\right)$ \\
\hline 1 & 3 & 19,5 & 5 & 11,5 & 8 & 64 \\
\hline 2 & 8 & 5,5 & 8 & 3 & 2,5 & 6,25 \\
\hline 3 & 8 & 5,5 & 8 & 3 & 2,5 & 6,25 \\
\hline 4 & 10 & 1 & 8 & 3 & -2 & 4 \\
\hline 5 & 6 & 10,5 & 5 & 11,5 & -1 & 1 \\
\hline 6 & 9 & 2,5 & 3 & 19 & $-16,5$ & 272,25 \\
\hline 7 & 4 & 17,5 & 8 & 3 & 14,5 & 210,25 \\
\hline 8 & 3 & 19,5 & 7 & 6 & 13,5 & 182,25 \\
\hline 9 & 5 & 15 & 8 & 3 & 12 & 144 \\
\hline 10 & 8 & 5,5 & 3 & 19 & $-13,5$ & 182,25 \\
\hline 11 & 9 & 2,5 & 6 & 8 & $-5,5$ & 30,25 \\
\hline 12 & 5 & 15 & 4 & 15,5 & $-0,5$ & 0,25 \\
\hline 13 & 6 & 10,5 & 3 & 19 & $-8,5$ & 72,25 \\
\hline 14 & 6 & 10,5 & 4 & 15,5 & -5 & 25 \\
\hline 15 & 5 & 15 & 5 & 11,5 & 3,5 & 12,25 \\
\hline 16 & 8 & 5,5 & 6 & 8 & $-2,5-$ & 6,25 \\
\hline 17 & 4 & 17,5 & 4 & 15,5 & 2 & 4 \\
\hline 18 & 6 & 10,5 & 5 & 11,5 & -1 & 1 \\
\hline 19 & 6 & 10,5 & 6 & 8 & 2,5 & 6,25 \\
\hline 20 & 6 & 10,5 & 4 & 15,5 & -5 & 25 \\
\hline & & & & $\sum \mathrm{d}^{2}=1255$ \\
\hline
\end{tabular}

\section{Uji Statistik Korelasi Spearman}

$$
\begin{aligned}
& r s=1-\frac{6 \sum d^{2}}{n\left(n^{2}-1\right)} \\
& r s=1-\frac{(6) \cdot(1255)}{20\left(20^{2}-1\right)}=r s=1-\frac{7530}{7980}=0,056
\end{aligned}
$$

6. Kesimpulan

Karena $\quad \mathrm{rs}_{\text {hitung }}=0,056 \leq \mathrm{rs}_{\text {tabel }}=0,447 \quad$ maka $\mathrm{H}_{0}$ diterima sehingga tidak ada hubungan yang signifikan antara tuntutan tugas dengan kepuasan kerja. 
89 | al-Khwarizmi, Volume III, Edisi 1, Maret 2015, Hal. 83 - 92.

\section{Kasus Wanita}

Contoh: Menghitung Korelasi Spearman antara Tuntutan Tugas $\left(\mathrm{X}_{2}\right)$ dengan Kepuasan Kerja $\left(\mathrm{Y}_{2}\right)$ pegawai wanita.

1. Hipotesis

$\mathrm{H}_{0}$ : Tidak ada hubungan antara Tuntutan Tugas dengan Kepuasan Kerja.

$\mathrm{H}_{1}$ : Ada hubungan antara Tuntutan Tugas dengan Kepuasan Kerja.

2. Nilai $\alpha$ dan rs tabel

$\alpha=5 \%=0,05, \mathrm{n}=20, \mathrm{rs}_{0,05 ; 20}=0,447$

3. Kriteria Pengambilan Keputusan

Nilai $r s_{\text {hitung }}>r s_{\text {tabel }}$ maka $\mathrm{H}_{0}$ ditolak

Nilai $r s_{\text {hitung }} \leq r s_{\text {tabel }}$ maka $\mathrm{H}_{0}$ diterima

4. Membuat Tabel Penolong Korelasi Spearman

Tabel Penolong Untuk Menghitung Korelasi Spearman

\begin{tabular}{|c|c|c|c|c|c|c|}
\hline NO & $\left(\mathrm{X}_{2}\right)$ & $\begin{array}{c}\text { Rank } \\
\left(\mathrm{X}_{2}\right)\end{array}$ & $\left(\mathrm{Y}_{2}\right)$ & $\begin{array}{c}\text { Rank } \\
\left(\mathrm{Y}_{2}\right)\end{array}$ & $\begin{array}{c}\mathrm{X}-\mathrm{Y} \\
(\mathrm{d})\end{array}$ & $\left(\mathrm{d}^{2}\right)$ \\
\hline 1 & 3 & 17,5 & 3 & 17 & 0,5 & 0,25 \\
\hline 2 & 3 & 17,5 & 6 & 7,5 & 10 & 100 \\
\hline 3 & 7 & 6 & 7 & 4 & 2 & 4 \\
\hline 4 & 3 & 17,5 & 3 & 17 & 0,5 & 0,25 \\
\hline 5 & 5 & 11,5 & 4 & 12 & $-0,5$ & 0,25 \\
\hline 6 & 7 & 6 & 4 & 12 & -6 & 36 \\
\hline 7 & 6 & 9,5 & 5 & 9,5 & 0 & 0 \\
\hline 8 & 7 & 6 & 7 & 4 & 2 & 4 \\
\hline 9 & 5 & 11,5 & 3 & 17 & $-5,5$ & 30,25 \\
\hline 10 & 6 & 9,5 & 7 & 4 & 5,5 & 30,25 \\
\hline 11 & 8 & 3 & 5 & 9,5 & $-6,5$ & 42,25 \\
\hline 12 & 4 & 13,5 & 3 & 17 & $-3,5$ & 12,25 \\
\hline 13 & 3 & 17,5 & 4 & 12 & 5,5 & 30,25 \\
\hline 14 & 11 & 2 & 7 & 4 & -2 & 4 \\
\hline 15 & 13 & 1 & 9 & 1 & 0 & 0 \\
\hline 16 & 3 & 17,5 & 3 & 17 & 0,5 & 0,25 \\
\hline 17 & 3 & 17,5 & 3 & 17 & 0,5 & 0,25 \\
\hline 18 & 7 & 6 & 6 & 7,5 & $-1,5$ & 2,25 \\
\hline 19 & 4 & 13,5 & 3 & 17,5 & $-3,5$ & 12,25 \\
\hline 20 & 7 & 6 & 7 & 4 & 2 & 4 \\
\hline & & & & \\
\hline
\end{tabular}

5. Uji Statistik Korelasi Spearman

$$
\begin{aligned}
& r s=1-\frac{6 \sum \mathrm{d}^{2}}{\mathrm{n}\left(\mathrm{n}^{2}-1\right)} \\
& \mathrm{rs}=1-\frac{(6) \cdot(313)}{20\left(20^{2}-1\right)}=\mathrm{rs}=1-\frac{1878}{7980}=0,765
\end{aligned}
$$


6. Kesimpulan

Karena $\quad \mathrm{rs}_{\text {hitung }}=0,765>\mathrm{rs}_{\text {tabel }}=0,447 \quad$ maka

$\mathrm{H}_{0}$ ditolak $\left(\mathrm{H}_{1}\right.$ diterima $)$ sehingga ada hubungan yang signifikan antara tuntutan tugas dengan kepuasan kerja.

Perhitungan korelasi spearman secara manual dan perhitungan korelasi spearman dengan software SPSS, dapat di lihat pada tabel sebagai berikut :

Tabel Nilai Korelasi Spearman

Perhitungan Manual

\begin{tabular}{|c|c|c|c|}
\hline \multirow{2}{*}{ No } & \multirow{2}{*}{ Variabel } & \multicolumn{2}{|c|}{$\begin{array}{c}\text { Korelasi } \\
\text { Spearman }\end{array}$} \\
\cline { 3 - 4 } & & Pria & Wanita \\
\hline 1 & $\begin{array}{c}\text { Peran Individu } \\
\text { Dalam Organisasi }\end{array}$ & $-0,248$ & 0,243 \\
\hline 2 & Tuntutan Tugas & 0,056 & 0,765 \\
\hline 3 & $\begin{array}{c}\text { Hubungan Dalam } \\
\text { Organisasi }\end{array}$ & 0,30 & 0,573 \\
\hline 4 & $\begin{array}{c}\text { Faktor Luar } \\
\text { Organisasi }\end{array}$ & $-0,104$ & 0,310 \\
\hline
\end{tabular}

Nilai Korelasi Spearman Dengan SPSS

\begin{tabular}{|c|c|c|c|}
\hline \multirow{2}{*}{ No } & \multirow{2}{*}{ Variabel } & \multicolumn{2}{|c|}{$\begin{array}{l}\text { Cortelation } \\
\text { coefficient }\end{array}$} \\
\hline & & Pria & Wanita \\
\hline 1 & $\begin{array}{l}\text { Peranan Incividua } \\
\text { dalam Organisasi }\end{array}$ & $-0,280$ & 0,195 \\
\hline 2 & Tuntutan Tugas & 0,020 & 0,752 \\
\hline 3 & $\begin{array}{c}\text { Hubungan Dalam } \\
\text { Organisasi }\end{array}$ & 0,252 & 0,546 \\
\hline 4 & $\begin{array}{l}\text { Faktor Luas } \\
\text { Otganisasi }\end{array}$ & $-0,136$ & 0,259 \\
\hline
\end{tabular}

Berdasarkan dua tabel tersebut, dapat diketahui bahwa untuk tuntutan tugas dan hubungan dalam organisasi pada pegawai pria serta peran individu dalam organisasi dan faktor luar organisasi pada pegawai wanita, tidak memiliki hubungan dengan kepuasan kerjanya, sedangkan untuk peran individu dalam organisasi dan faktor luar organisasi pada pegawai pria, arah hubungannya tidak searah atau berlawanan, tetapi karna nilai $r$ hitungnya $<$ nilai $r$ tabel, maka tidak ada hubungan. Untuk tuntutan tugas pada pegawai wanita, menunjukan derajat asosiasi yang tinggi (hubungan yang kuat) dengan kepuasan kerjanya, sedangkan hubungan dalam organisasi, mempunyai hubungan yang substansial dengan kepuasan kerja pegawai wanita.

\section{Kesimpulan}

1. Tidak ada hubungan antara variabel-variabel stres kerja dengan variabel kepuasan kerja pegawai pria pada Dinas Perhubungan Kota Ambon.

2. Dari beberapa variabel stress kerja wanita, hanya 2 variabel stres kerja yang mempunyai hubungan dengan kepuasan kerja wanita pada Dinas Perhubungan Kota Ambon. 
91 | al-Khwarizmi, Volume III, Edisi 1, Maret 2015, Hal. 83 - 92.

3. Dari kesimpulan 1 dan 2, dapat di lihat perbandingan antara stress kerja pegawai pria dan wanita yaitu pegawai wanita memiliki dua variabel yang mempunyai hubungan dengan kepuasan kerja yaitu tuntutan tugas dan hubungan dalam organisasi yang berarti apabila stres kerja wanita dalam hal ini tuntutan tugas dan hubungan dalam organisasi meningkat maka kepuasan kerja wanita juga meningkat, sedangkan pada pegawai pria yang variabel - variabelnya tidak ada hubungan dengan kepuasan kerja berarti apabila stress kerja pria meningkat maka kepuasan kerja pria akan menurun bagitupun sebaliknya. 


\section{DAFTAR PUSTAKA}

Arokhman. 2009. Bab III Statistik Non Parametrik, http://arokhman.blog.unsoed.ac.id/files/2009/06/3-statistiknonparametrik.pdf diakses 11 Pebruari 2015.

Departemen Biostatistik FKM UI. 2009. Statistik Non Parametrik, http://repository.ui.ac.id/contents/koleksi/11/7263bdba0cd59d 61cd2ced60bc3c4cf035dd81ae.pdf diakses 11 Pebruari 2015.

Ghozali, Imam. 2009. Aplikasi Analisis Multivariate dengan Program SPSS. Semarang:Badan Penerbit Universitas Diponegoro.

Hafni, W. 2010. Analisis Hubungan Antara Stres Kerja Dengan Kepuasan Kerja Karyawan Berdasarkan Gender. Semarang: Badan Penerbit Universitas Diponegoro.

Hermawati, T. 2007. Budaya Jawa dan Kesetaraan Gender. Jurnal Komunikasi Massa. Vol. 1 No. 1, pp 18-24.

Heryawan, Ahmad. 2009. Hakikat Kesetaraan Gender, http://www.ahmadheryawan.com/kolom/94-kolom/2722hakikat-kesetaraan-dan-keadilan-gender.pdf diakses 11 Pebruari 2015.

Leila, G. 2002. Stres dan Kepuasan Kerja. Jurnal USU Digital Library.

Martoyo, S. 2000. Manajemen Sumber Daya Manusia Edisi 4. Yogyakart:BPFE.

Mas'ud, Fuad. 2004. Survai Diagnosis Organisasional Konsep dan Aplikasi. Semarang:Badan Penerbit Universitas Diponegoro.

Munandar, A. S. 2008. Psikologi Industri dan Organisasi. Jakarta:Penerbit Universitas Indonesia.

Robbins, S. P. 2007. Perilaku Organisasi. Jakarta:PT Macanan Jaya Cemerlang.

http://nurhadi1602.blogspot.com/2013/11/kesetaraan-gender-danstatus-sosial_6344.html. Diakses 11 Pebruari 2015.

https://www.google.com/search?q=sismik\&ie=utf-8\&oe=utf8.Diakses26 Pebruari 2015.

http://id.wikipedia.org/wiki/Kepuasan_Kerja. Diakses 26 Pebruari 2015. 